\title{
Progression to hypertension in the non-hypertensive participants in the Flemish Study on Environment, Genes and Health Outcomes
}

\author{
Haifeng Zhang ${ }^{a, b}$, Lutgarde Thijs ${ }^{a}$, Tatiana Kuznetsova ${ }^{a}$, Robert H. Fagard ${ }^{a}$, \\ Xinli Li ${ }^{\mathrm{b}}$ and Jan A. Staessen ${ }^{\mathrm{a}}$
}

Objective To evaluate the consistency between a randomly recruited Western European population and the participants of the Framingham Heart Study, with respect to the rates and determinants of progression to hypertension.

Methods Among the non-hypertensive individuals enrolled in the Flemish Study on Environment, Genes and Health Outcomes, we assessed progression from optimal $(<120 / 80 \mathrm{mmHg})$, normal (120-129/80-84 $\mathrm{mmHg})$ and high-normal (130-139/85-89 $\mathrm{mmHg}$ ) blood pressure to hypertension $(\geq 140 / 90 \mathrm{mmHg}$ ). Our analysis included 781 women and 675 men (age range 10-77 years) who were followed up for a median of 4.6 years (interquartile range 2.4-8.1 years). Our statistical methods included Kaplan-Meier survival function estimates, the log-rank test and multiple Cox regression.

Results In individuals younger than $\mathbf{5 0}$ years, 4-year progression rates associated with optimal, normal and high-normal blood pressure were 7.4\% [95\% confidence interval (Cl) 5.5-9.3], 17.9\% (95\% Cl 14.3-21.6) and $24.5 \%$ (95\% Cl 18.7-30.2), respectively. Corresponding 4-year rates of progression for individuals aged $\mathbf{5 0}$ years or older were $16.4 \%$ (95\% Cl 11.2-22.5), 26.3\%

(95\% Cl 19.8-32.9) and 54.0\% (95\% Cl 45.7-62.3), respectively. In multivariate Cox regression, blood pressure category and body mass index at baseline were strong predictors of hypertension. Before the age of $\mathbf{5 0}$ years, male sex and a fast heart rate were also forerunners of hypertension.

\section{Introduction}

In 2001, the Framingham investigators [1] assessed the transition to hypertension from optimal, normal and highnormal blood pressure, as defined by the Joint National Committee on the Prevention, Detection, Evaluation and Treatment of High Blood Pressure (JNC VI) [2], or the World Health Organization and the International Society of Hypertension (WHO-ISH) [3]. The Framingham findings [1] have implications for the early detection of hypertension in non-hypertensive individuals and have informed several guidelines for the diagnosis and management of hypertension [4,5]. Wolf-Maier and colleagues [6], in a retrospective review of eight surveys on hypertension, noticed average blood pressure differences between North America and Western Europe
Conclusions The stepwise increase in incidence of hypertension across the three non-hypertensive blood pressure categories in our cohort was similar to that observed in the Framingham Heart Study. The Framingham findings, which have informed several guidelines, can be extrapolated to a Western European population. J Hypertens 24:1719-1727 (c) 2006 Lippincott Williams \& Wilkins.

Journal of Hypertension 2006, 24:1719-1727

Keywords: blood pressure, general population, hypertension, prospective study

aStudies Coordinating Centre, Division of Hypertension and Cardiovascular Rehabilitation, Department of Cardiovascular Diseases, University of Leuven, Leuven, Belgium and ${ }^{b}$ Department of Cardiology, the First Affiliated Hospital, Nanjing Medical University, Nanjing, China

Correspondence and requests for reprints to Jan A. Staessen, MD, PhD, Studies Coordinating Centre, Division of Hypertension and Cardiovascular Rehabilitation Unit, Department of Cardiovascular Diseases, University of Leuven, Campus Gasthuisberg, Herestraat 49, Box 702, B-3000 Leuven, Belgium

Tel: +32 1634 7104; fax: +32 1634 7106;

e-mail: jan.staesssen@med.kuleuven.be

Sponsorship: Research included in this study was partially funded by the European Union (grants IC15-CT98-0329-EPOGH and QLGI-CT-2000-01137EURNETGEN), the Fonds voor Wetenschappelijk Onderzoek Vlaanderen, Ministry of the Flemish Community, Brussels, Belgium (grants G.0424.03 and G.0575.06), and the Katholieke Universiteit Leuven, Leuven, Belgium (grants OT/99/28, OT/00/25 and OT/05/49).

Conflicts of interest: None.

Received 12 January 2006 Revised 6 March 2006 Accepted 28 April 2006

of $9 \mathrm{mmHg}$ systolic and $6 \mathrm{mmHg}$ diastolic, with even larger contrasts between individual countries. WolfMaier and colleagues' observations [6] raise the issue of the generalizability of the Framingham results [1]. Our objectives were therefore to assess, in non-hypertensive individuals randomly recruited from a Western European population, consistency with the Framingham Heart Study [1] in the rates and determinants of the progression to hypertension.

\section{Methods}

Study population

The Ethics Committee of the University of Leuven approved the Flemish Study on Environment, Genes and Health Outcomes [7,8]. From August 1985 until 
November 1990, a random sample of the households living in a geographically defined area in northern Belgium was investigated, with the aim of recruiting an equal number of participants in each of six subgroups by sex and age (20-39, 40-59 and $\geq 60$ years) [7]. All household members aged 20 years or older were invited to take part, until the quota of the relevant sex-age group had been fulfilled. To further the study of the role of genetic factors, from June 1996 until May 2005, nuclear families including children who were at least 10 years old were recruited using the former study individuals as index persons. The participants or the parents or custodians of underaged offspring gave informed written consent [8].

The study population included 2966 individuals, of whom $148(5.0 \%)$ died before they could be followed up. The participation rate among the individuals contacted averaged $64.3 \%$. To study the age-related trends in systolic (SBP) and diastolic (DBP) blood pressures, we excluded all blood pressure measurements at baseline and follow-up that were obtained while the individual was receiving antihypertensive drug treatment. To study the rates of transition to hypertension, we selected 1943 individuals whose blood pressure had been measured at least twice with a minimal interval between visits of 1 year. Of those, we excluded 487 because they were already hypertensive at baseline $(n=474)$, had a history of myocardial infarction $(n=31)$ or had heart failure $(n=12)$ (disorders that directly decrease blood pressure and necessitate the use of medications that can further reduce blood pressure) [1].

The remaining 1456 individuals were divided into two subgroups. The first comprised 1119 who had their baseline blood pressure measured before the age of 50 years. The second consisted of 337 individuals enrolled at 50 years or later and 98 individuals also included in the younger subgroup. These 98 participants had no history of hypertension, myocardial infarction or heart failure, and after 50 years of age had at least two follow-up visits, of which the first was used as baseline in the older age group.

\section{Data collection}

At the enrollment home visit and at follow-up either at the participant's home or at a local examination center $[7,8]$, trained nurses measured the participant's anthropometric characteristics, counted the heart rate over $1 \mathrm{~min}$, and obtained five consecutive blood pressure readings, which were averaged for analysis. Body mass index (BMI) was calculated as weight in kilograms divided by the square of height in metres. The nurses administered a questionnaire enquiring into each individual's medical history, smoking and drinking habits, and intake of medications. The questionnaire also provided detailed information on the total number of hours spent in recreational and occupational activities, including attending school in the case of younger people [9]. With the use of published tables [10], we estimated the energy spent in physical activity from body weight, the time devoted to sports and work, and the types of physical activity. Venous blood samples were drawn for measurement of serum total cholesterol and blood glucose concentrations. Diabetes mellitus was defined as a blood glucose concentration of at least $7.0 \mathrm{mmol} / \mathrm{l}$ fasting or $11.1 \mathrm{mmol} / \mathrm{l}$ random, or the use of antidiabetic drugs [11]. The participants also collected a 24-h urine sample in a wide-necked plastic container, for the measurement of electrolytes.

We classified the 1456 participants without hypertension into those with optimal, normal or high-normal blood pressure. For those aged 18 years or older, we applied the JNC VI [2] or WHO-ISH [3] blood pressure thresholds. Optimal blood pressure was defined as SBP less than $120 \mathrm{mmHg}$ and DBP less than $80 \mathrm{mmHg}$, normal blood pressure as SBP $120-129 \mathrm{mmHg}$ or DBP $80-84 \mathrm{mmHg}$ and high-normal blood pressure as SBP $130-139 \mathrm{mmHg}$ or DBP $85-89 \mathrm{mmHg}$. For children and adolescents, we used the thresholds specified by the National High Blood Pressure Education Program Working Group (HBP-CA) [12], which are stratified by sex, age and height percentiles. 'Optimal' was a blood pressure less than the 50th percentiles for SBP and DBP, 'normal' blood pressure was between the SBP or DBP 50th and 89th percentiles, and 'high-normal' blood pressure was between the 90th and 94th percentiles. We made use of the percentiles of height currently representative for Flemish youngsters [13]. If SBP or DBP readings belonged to different categories, the higher of the two readings was used for classification. If, in older adolescents, the blood pressure thresholds described above were greater than the JNC VI [2] or WHO-ISH [3] criteria, the latter were applied.

The number of follow-up visits was $1,2,3$, or $4+$ in 606 , 399, 246 and 205 participants, respectively. During follow-up, we reclassified participants remaining normotensive according to their blood pressure status at the last available follow-up visit. Those becoming hypertensive were reclassified at the first follow-up visit when their blood pressure exceeded the JNC VI [2] or WHO-ISH [3] criteria in adults or the HBP-CA [12] criteria in children or adolescents, or when they were taking antihypertensive drugs.

\section{Statistical analysis}

We used the SAS software package (SAS Institute, Inc. Cary, North Carolina, USA), version 9.1.3, for database management and statistical analysis. We reported the central tendency and spread of normally and nonnormally distributed data as mean $\pm \mathrm{SD}$ and as median with interquartile range, respectively. To compare 
means, medians and proportions, we used analysis of variance with Dunnett's test, Wilcoxon's test, and Fisher's exact test, respectively, with Bonferroni's correction of the significance levels, if appropriate.

First, we evaluated the average age trends in blood pressure for women and men, based on cross-sectional or longitudinal data, as described by Kannel and Gordon [14]. Next, we constructed sex-specific transition matrices in which each participant's blood pressure categories at baseline and follow-up were cross-tabulated. We examined the crude incidence rates of hypertension for participants in each of the three non-hypertensive blood pressure categories by age group, using KaplanMeier survival function estimates and the log-rank test. The adjusted 4-year and 8-year incidence rates were calculated using multiple Cox regression, with adjustment for the baseline variables sex, age, BMI, heart rate, smoking and the time-dependent variable BMI change during follow-up. In sensitivity analyses, we also adjusted for cohort effects (recruitment before 1996 or later) or supplementary baseline characteristics, including alcohol intake, the urinary sodium: potassium ratio, or the energy spent in recreational and occupational physical activity.

In 1229 individuals (84.4\%), the first follow-up visit took place more than 2 years after enrollment, therefore we also extrapolated the 2-year incidence rate of hypertension from the 4-year rate, assuming constant risk, according to the formula [1]: 2-year rate $=1-\sqrt{ }(1-4$-year rate). The incidence of hypertension in individuals with optimal, normal and high-normal blood pressure was compared by introduction of two design variables in the Cox models and the computation of the relative hazard ratios and confidence intervals associated with these two predictor variables. Participants with optimal blood pressure at baseline served as the referent group. To correct for regression dilution bias, we used the blood pressure readings obtained at a follow-up visit at the individuals' homes within 1 year of enrollment and we applied the parametric approach as described previously $[15,16]$.

We used multiple linear regression analysis to investigate the association between the changes in blood pressure and percentage changes in BMI, adjusting for the blood pressure at baseline, duration of follow-up, and the same covariates as in Cox regression. All tests were two-sided and significance was accepted at a $P$ value of 0.05 or less.

\section{Results}

\section{Baseline characteristics}

At enrollment, 432 women (55.3\%) and 230 men (34.1\%) had an optimal blood pressure, 225 women $(28.8 \%)$ and 280 men $(41.5 \%)$ had normal blood pressure, and the remaining 124 women (15.9\%) and 165 men $(24.4 \%)$ had high-normal blood pressure. Table 1 shows the clinical characteristics of the participants in the two age groups according to the blood pressure category at baseline. Age at baseline ranged from 10 to 49 years and from 50 to 77 years, in the younger and older age groups, respectively. The numbers of patients with diabetes mellitus at baseline were eight (1.3\%) and three $(0.6 \%)$ among younger women and men, and nine $(3.9 \%)$ and seven (3.4\%) among the older individuals.

\section{Age trends in blood pressure}

Figure 1a shows the average age trends in blood pressure in untreated individuals by sex, based on cross-sectional $(n=2643)$ and longitudinal $(n=1348)$ data.

\section{Progression to hypertension}

Table 2 shows the blood pressure category of participants at follow-up according to their baseline category. Progression to hypertension was about twice as frequent in the older subgroup [196 of 435 individuals (45.1\%)] than in the younger subgroup [273 of 1119 individuals (24.4\%)]. In those younger than 50 years at enrollment, progression to hypertension occurred on the basis of an increase in SBP alone in 49 participants (17.9\%), an increase in DBP alone in $103(37.7 \%)$, as a result of crossing both the SBP and the DBP thresholds in 59 (21.6\%), and on the basis of the use of antihypertensive agents in 62 (22.7\%). In the older subgroup, progression to hypertension was determined on the basis of an increase in SBP alone in 70 participants (35.7\%; $P<0.0001$ compared with the younger subgroup), DBP alone in $19(9.7 \% ; P<0.0001)$, as a result of crossing both the SBP and the DBP thresholds in $34(17.3 \%$; $P=0.29)$, and on the basis of the use of antihypertensive agents in $73(37.2 \% ; P=0.0009)$. Table 3 lists changes in SBP and DBP from baseline to last follow-up for individuals remaining off antihypertensive treatment, categorized by baseline blood pressure.

\section{Determinants of progression to hypertension}

In unadjusted analyses (Fig. 1b and c), the blood pressure category at baseline and age group were important determinants of the progression to hypertension. In multivariate Cox regression (Table 4), compared with optimal blood pressure, normal blood pressure at baseline was associated with 2.57 and 1.71 increased risks of hypertension in the younger and older subgroups, respectively. High-normal blood pressure was associated with 3.65 and 4.34 greater risks. BMI at baseline was a consistent predictor of the risk of hypertension, irrespective of age subgroup. Sex, heart rate and non-smoking at baseline were also associated with a greater risk of hypertension in the younger, but not older, subgroup. In both young and old individuals, the interaction term between BMI and smoking status at baseline was not statistically significant $(P>0.24)$. 
Table 1 Characteristics of the study participants by age group, sex and blood pressure category at baseline ${ }^{a}$

\begin{tabular}{|c|c|c|c|c|c|c|}
\hline \multirow[b]{2}{*}{ Measurement $^{\mathrm{b}}$} & \multicolumn{3}{|c|}{ Women } & \multicolumn{3}{|c|}{ Men } \\
\hline & Optimal & Normal & High-normal & Optimal & Normal & High-normal \\
\hline \multicolumn{7}{|l|}{ Age $<50$ years } \\
\hline Number of individuals & 380 & 168 & 59 & 175 & 222 & 115 \\
\hline \multicolumn{7}{|l|}{ Baseline characteristics } \\
\hline Age (years) & $33.1 \pm 9.2$ & $31.9 \pm 11.3$ & $36.8 \pm 9.4 *$ & $33.3 \pm 10.1$ & $31.9 \pm 10.6$ & $34.4 \pm 8.9$ \\
\hline Systolic blood pressure $(\mathrm{mmHg})$ & $109.1 \pm 6.6$ & $120.4 \pm 6.6 *$ & $131.1 \pm 4.2 *$ & $112.3 \pm 5.9$ & $122.6 \pm 5.9 *$ & $131.3 \pm 5.8 *$ \\
\hline Diastolic blood pressure $(\mathrm{mmHg})$ & $67.8 \pm 6.3$ & $73.7 \pm 7.5 *$ & $81.2 \pm 6.4 *$ & $68.2 \pm 6.6$ & $74.8 \pm 6.6 *$ & $80.9 \pm 7.0 *$ \\
\hline Heart rate (beats/min) & $70.3 \pm 9.3$ & $73.7 \pm 10.3 *$ & $74.7 \pm 9.5 *$ & $66.1 \pm 9.0$ & $68.1 \pm 9.2$ & $68.6 \pm 9.6$ \\
\hline Body mass index $\left(\mathrm{kg} / \mathrm{m}^{2}\right)$ & $23.0 \pm 3.8$ & $24.0 \pm 4.6 *$ & $26.5 \pm 5.6 *$ & $23.8 \pm 3.5$ & $24.2 \pm 3.3$ & $25.9 \pm 3.4 *$ \\
\hline Serum total cholesterol $(\mathrm{mmol} / \mathrm{l})$ & $5.05 \pm 0.94$ & $5.17 \pm 1.06$ & $5.32 \pm 1.00$ & $5.16 \pm 1.22$ & $5.14 \pm 1.19$ & $5.31 \pm 1.13$ \\
\hline Blood glucose (mmol/l) & $4.64 \pm 0.93$ & $4.85 \pm 1.02$ & $4.95 \pm 1.41 *$ & $4.63 \pm 0.91$ & $4.72 \pm 0.89$ & $4.84 \pm 1.11$ \\
\hline Urinary sodium : potassium ratio & $2.87 \pm 1.51$ & $2.87 \pm 1.13$ & $3.04 \pm 1.09$ & $2.91 \pm 1.19$ & $2.90 \pm 1.08$ & $2.96 \pm 1.22$ \\
\hline Physical activity $\left(10^{3} \times \mathrm{kcal}\right)$ & $1.3(0.8-2.0)$ & $1.2(0.8-2.0)$ & $1.5(1.0-2.0)$ & $1.7(1.2-2.6)$ & $1.6(1.1-2.6)$ & $1.8(1.2-2.8)$ \\
\hline Smoker & 134 (35.3) & $62(36.9)$ & 19 (32.2) & $62(35.4)$ & $67(30.2)$ & $48(41.7)$ \\
\hline Alcohol intake & 39 (10.3) & $22(13.1)$ & 9 (15.3) & $62(35.4)$ & $80(36.0)$ & $47(40.9)$ \\
\hline \multicolumn{7}{|l|}{ Follow-up } \\
\hline Duration of follow-up (years) & $5.0(3.4-9.4)$ & $4.4(2.2-8.8) *$ & $4.2(2.0-7.5) *$ & $4.8(2.5-8.7)$ & $4.6(2.4-7.1)$ & $4.0(2.2-7.2) *$ \\
\hline Change in body mass index (\%) & $4.1(-1.0$ to 9.1$)$ & $4.7(-0.1$ to 7.9$)$ & $2.2(-1.1$ to 7.6$)$ & $3.7(-0.6$ to 8.1$)$ & 3.6 (0 to 7.7$)$ & $1.9(-1.3$ to 6.0$) *$ \\
\hline \multicolumn{7}{|l|}{ Age $\geq 50$ years } \\
\hline Number of individuals & 76 & 78 & 78 & 69 & 72 & 62 \\
\hline \multicolumn{7}{|l|}{ Baseline characteristics } \\
\hline Age (years) & $55.6 \pm 5.1$ & $57.7 \pm 6.1$ & $58.6 \pm 6.8 *$ & $57.3 \pm 6.5$ & $57.7 \pm 6.8$ & $58.2 \pm 6.9$ \\
\hline Systolic blood pressure (mmHg) & $111.3 \pm 6.3$ & $123.0 \pm 4.3 *$ & $133.4 \pm 4.4 *$ & $112.8 \pm 5.7$ & $123.8 \pm 4.4 *$ & $133.9 \pm 4.9 *$ \\
\hline Diastolic blood pressure $(\mathrm{mmHg})$ & $70.0 \pm 5.7$ & $76.3 \pm 5.1 *$ & $80.3 \pm 5.6 *$ & $70.0 \pm 5.9$ & $77.2 \pm 4.9 *$ & $80.1 \pm 6.5 *$ \\
\hline Heart rate (beats/min) & $70.6 \pm 7.7$ & $70.9 \pm 8.5$ & $73.2 \pm 8.7$ & $68.5 \pm 10.5$ & $68.5 \pm 9.1$ & $68.0 \pm 9.6$ \\
\hline Body mass index $\left(\mathrm{kg} / \mathrm{m}^{2}\right)$ & $25.3 \pm 3.9$ & $26.4 \pm 4.1$ & $27.8 \pm 4.7 *$ & $25.8 \pm 2.8$ & $26.4 \pm 3.4$ & $26.6 \pm 3.1$ \\
\hline Serum total cholesterol $(\mathrm{mmol} / \mathrm{l})$ & $6.17 \pm 1.09$ & $6.20 \pm 1.24$ & $6.66 \pm 1.44 *$ & $6.08 \pm 1.19$ & $5.97 \pm 0.88$ & $6.19 \pm 1.31$ \\
\hline Blood glucose $(\mathrm{mmol} / \mathrm{l})$ & $5.07 \pm 1.37$ & $5.32 \pm 1.39$ & $5.43 \pm 2.01$ & $5.33 \pm 2.36$ & $5.17 \pm 1.35$ & $5.31 \pm 2.10$ \\
\hline Urinary sodium : potassium ratio & $2.23 \pm 0.92$ & $2.58 \pm 1.08$ & $2.55 \pm 0.96$ & $2.70 \pm 1.37$ & $2.93 \pm 2.41$ & $2.78 \pm 0.92$ \\
\hline Physical activity $\left(10^{3} \times \mathrm{kcal}\right)$ & $2.0(0.1-2.1)$ & $2.0(0.4-2.1)$ & $2.0(1.0-2.1)$ & $0.6(0.1-2.5)$ & $0.4(0.1-1.0)$ & $0.8(0.1-1.7)$ \\
\hline Smoker & $20(26.3)$ & $17(21.8)$ & $11(14.1)$ & $33(47.8)$ & $32(44.4)$ & 21 (33.9) \\
\hline Alcohol intake & $12(15.8)$ & $13(16.7)$ & $8(10.3)$ & $21(30.4)$ & $28(38.9)$ & $29(46.8)$ \\
\hline \multicolumn{7}{|l|}{ Follow-up } \\
\hline Duration of follow-up (years) & $6.0(3.5-8.1)$ & $4.0(1.9-7.2) *$ & $2.9(2.0-4.2) *$ & $6.1(3.9-9.4)$ & $5.3(2.5-7.2)$ & $3.1(1.8-4.9) *$ \\
\hline Change in body mass index (\%) & $-0.4(-3.9$ to 6.2$)$ & $2.6(-0.5$ to 6.1$)$ & $0.5(-3.5$ to 4.5$)$ & $2.2(-1.7$ to 9.4$)$ & $0.7(-4.1$ to 7.2$)$ & $-0.4(-2.9$ to 4.9$) *$ \\
\hline
\end{tabular}

an individuals younger than 18 years, blood pressure categories were defined according to the thresholds specified by the National High Blood Pressure Education Program Working Group on High Blood Pressure in Children and Adolescents [12]. In participants aged 18 years or older, blood pressure categories relied on the guidelines of the Joint National Committee on the Prevention, Detection, Evaluation and Treatment of High Blood Pressure [2] and the criteria of the World Health Organization and International Society of Hypertension [3]. ' $V a l u e s$ are number, mean $\pm \mathrm{SD}$, number (\%), or median (interquartile range). Systolic and diastolic blood pressures were averages of five consecutive readings obtained at the enrollment home visit. Body mass index is weight in kilograms divided by the square of the height in metres. To convert values for total cholesterol to $\mathrm{ml} / \mathrm{dl}$, divide by 0.02586 . To convert values for glucose to $\mathrm{ml} / \mathrm{dl}$, divide by 0.05551 . $*$ Significant difference $(P \leq 0.05$ with Bonferroni's adjustment applied, compared with individuals with optimal blood pressure.

With cumulative adjustments applied as in Table 4, alcohol intake (yes/no), the urinary sodium : potassium ratio, and the energy spent in recreational or occupational physical activity did not significantly refine the prediction of hypertension (data not shown). At recruitment, compared with those recruited later, individuals enrolled before 1996 had greater SBP $(120.3 \mathrm{mmHg}$ compared with $117.1 \mathrm{mmHg} ; \quad P<0.0001)$, but similar DBP (73.1 $\mathrm{mmHg}$ compared with $72.6 \mathrm{mmHg} ; \quad P=0.23$ ), and during follow-up had a similar risk of developing hypertension (5.03 compared with 5.22 cases per 100 person-years of follow-up; $P=0.74)$. Further adjustment for recruitment before 1996 or later did not materially change the hazard ratios reported in Table 4 (data not shown).

In continuous analyses of individuals remaining untreated at baseline and throughout follow-up, we evaluated the relationship between the change in blood pressure from baseline to last follow-up and the corres- ponding percentage change in BMI. We adjusted these analyses for the baseline blood pressure, duration of follow-up, and the same covariates as in Cox regression. In younger individuals, a $5 \%$ increment in BMI was associated with blood pressure increases, amounting to $1.85 \mathrm{mmHg}$ SBP [95\% confidence interval (CI) $1.43-$ $2.27 \mathrm{mmHg} ; P<0.0001]$ and $1.17 \mathrm{mmHg}$ DBP $(95 \%$ CI $0.81-1.52 \mathrm{mmHg} ; P<0.0001)$. In the older subgroup, the corresponding estimates were $0.76 \mathrm{mmHg}(95 \% \mathrm{CI}$ $-0.22-1.73 \mathrm{mmHg} ; P=0.13)$ and $0.52 \mathrm{mmHg}(95 \% \mathrm{CI}$ $-0.11-1.15 \mathrm{mmHg} ; P=0.11)$, respectively.

\section{Correction for regression dilution bias}

To correct for regression dilution bias, we first subdivided the distributions of the blood measurements obtained at recruitment and within 1 year of enrollment according to quintiles of the baseline blood pressure. At baseline, the differences between the blood pressure means of the lowest and highest quintiles were $28.8 \mathrm{mmHg}$ SBP and $22.5 \mathrm{mmHg}$ DBP. At the follow-up visit within 1 year 

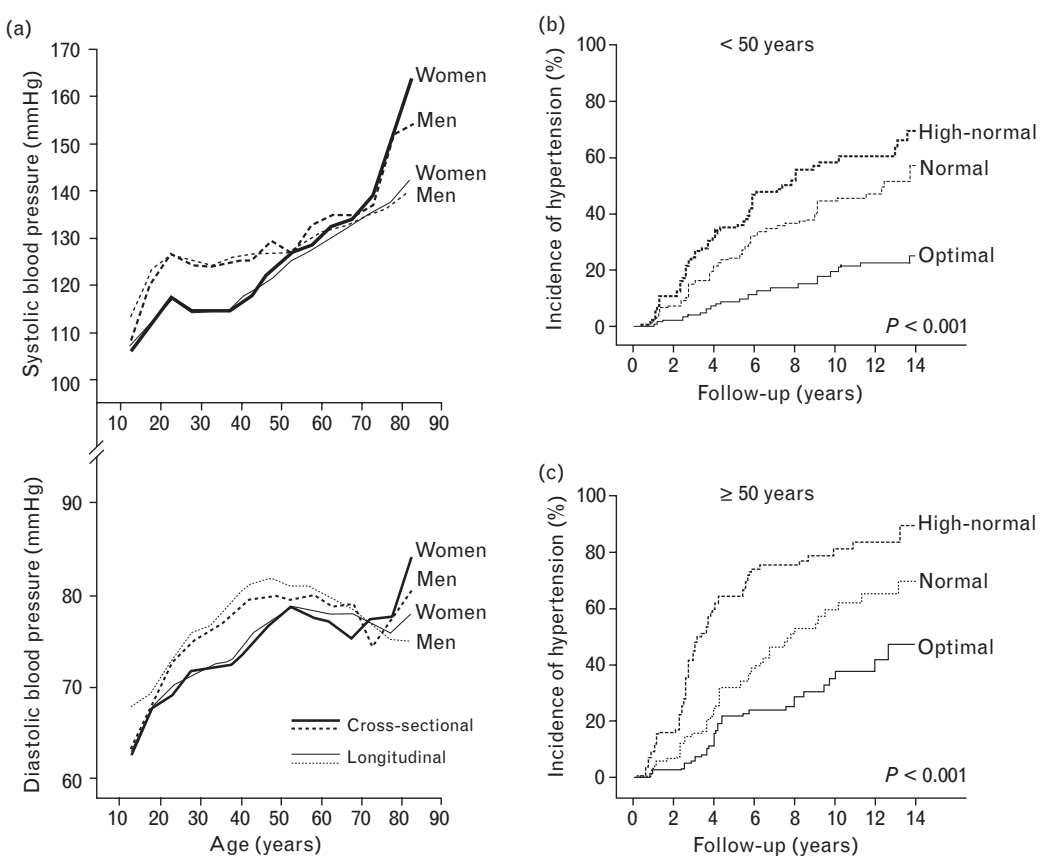

Blood pressure in the Flemish Study on Environment, Genes and Health Outcomes. (a) Average age trends in untreated women and men, based on cross-sectional data $(n=2643)$ or longitudinal data $(n=1348)$. (b), (c) Kaplan-Meier estimates for the transition to hypertension from optimal, normal or high-normal blood pressure according to age subgroup at baseline. $P$ values for the overall differences between the blood pressure categories are based on the log-rank test.

of enrollment, these differences had decreased to 21.3 and $17.0 \mathrm{mmHg}$, respectively. These observations suggested that the relationships between progression to hypertension and baseline blood pressure category as reported in Table 4 were about 1.3 times steeper for the usual compared with the baseline blood pressure. In younger individuals, the hazard ratios corrected for regression dilution bias were therefore 3.41 (95\% CI 2.30-5.04) for progression from normal blood pressure and 5.38 (95\% CI 3.46-8.36) for progression from highnormal blood pressure, compared with progression from optimal blood pressure to hypertension (referent group).
In the older subgroup, the corresponding relative hazard ratios, corrected for regression dilution bias, were 2.01 (95\% CI $1.19-3.43)$ and 6.74 (95\% CI $4.08-11.15)$, respectively.

\section{Rates of incidence of hypertension}

Table 5 shows adjusted 4 -year and 8 -year incidence rates of hypertension. We also extrapolated the 2-year rates from the 4-year rates, assuming constant risk. In the younger subgroup, the 2-year rates, while accounting for the same covariates as in Table 4 , were $3.8 \%$ for individuals with optimal blood pressure and 9.4 and

Table 2 Change in blood pressure category on follow-up according to baseline category ${ }^{a}$

\begin{tabular}{|c|c|c|c|c|}
\hline \multirow[b]{2}{*}{ Age and blood pressure category at baseline } & \multicolumn{4}{|c|}{ Blood pressure category on follow-up } \\
\hline & Optimal & Normal & High-normal & Hypertension \\
\hline \multicolumn{5}{|l|}{ Age $<50$ years } \\
\hline Optimal & $320(57.7)$ & $119(21.4)$ & $43(7.7)$ & $73(13.2)$ \\
\hline Normal & $104(26.7)$ & $118(30.3)$ & $46(11.8)$ & $122(31.3)$ \\
\hline High-normal & $22(12.6)$ & $48(27.6)$ & $26(14.9)$ & $78(44.8)$ \\
\hline \multicolumn{5}{|l|}{ Age $\geq 50$ years } \\
\hline Optimal & 50 (34.5) & $31(21.4)$ & $25(17.2)$ & 39 (26.9) \\
\hline Normal & $36(24.0)$ & $28(18.7)$ & $26(17.3)$ & $60(40.0)$ \\
\hline High-normal & $9(6.4)$ & $13(9.3)$ & $21(15.0)$ & 97 (69.3) \\
\hline
\end{tabular}

Values are number (\%). ${ }^{a}$ In individuals younger than 18 years, blood pressure categories were defined according to the thresholds specified by the National High Blood Pressure Education Program Working Group on High Blood Pressure in Children and Adolescents [12]. In participants aged 18 years or older, blood pressure categories relied on the guidelines of the Joint National Committee on the Prevention, Detection, Evaluation and Treatment of High Blood Pressure [2] and the criteria of the World Health Organization and International Society of Hypertension [3]. 
Table 3 Blood pressure changes from baseline to last follow-up according to baseline blood pressure category in untreated individuals $^{a}$

\begin{tabular}{lccc}
\hline & \multicolumn{3}{c}{ Blood pressure category at baseline ${ }^{\mathrm{b}}$} \\
\cline { 2 - 4 } & Optimal & Normal & High-normal \\
\hline Age $<50$ years & \multicolumn{3}{c}{} \\
$\quad$ Number of individuals & 532 & 372 & 153 \\
$\quad$ Systolic blood pressure $(\mathrm{mmHg})$ & $+6.6 \pm 11.4$ & $+3.0 \pm 12.1$ & $-1.7 \pm 11.5$ \\
$\quad$ Diastolic blood pressure $(\mathrm{mmHg})$ & $+5.7 \pm 9.9$ & $+4.6 \pm 10.0$ & $+1.5 \pm 10.6$ \\
Age $\geq 50$ years & & & \\
$\quad$ Number of individuals & 127 & 123 & 112 \\
Systolic blood pressure $(\mathrm{mmHg})$ & $+12.0 \pm 12.7$ & $+6.2 \pm 13.7$ & $+6.6 \pm 12.9$ \\
Diastolic blood pressure $(\mathrm{mmHg})$ & $+5.6 \pm 8.5$ & $+1.3 \pm 9.9$ & $+2.7 \pm 8.9$ \\
\hline
\end{tabular}

Values are number, or mean \pm SD. andividuals receiving antihypertensive treatment at follow-up were excluded. bIn individuals younger than 18 years, blood pressure categories were defined according to the thresholds specified by the National High Blood Pressure Education Program Working Group on High Blood Pressure in Children and Adolescents [12]. In participants aged 18 years or older, blood pressure categories relied on the guidelines of the Joint National Committee on the Prevention, Detection, Evaluation and Treatment of High Blood Pressure [2] and the criteria of the World Health Organization and International Society of Hypertension [3].
$13.1 \%$ for those with normal or high-normal blood pressure, respectively. In the older subgroup, the corresponding estimates were $8.5,14.2$ and $32.2 \%$, respectively (Table 5). Extrapolation of the 2-year rates from the 8 -year rates produced similar results (data not shown).

\section{Discussion}

Our study reports on the progression from optimal, normal and high-normal blood pressures to hypertension in a European population, applying JNG VI [2] or WHO-ISH [3] criteria. We replicated the estimates obtained by the Framingham investigators in 9845 individuals aged 35-94 years. In individuals younger than 65 years, the 4 -year transition rates were 5.3, 17.6 and $37.3 \%$, respectively; in older individuals they were 16.0 , 25.5 and $49.5 \%$ [1]. Our findings therefore suggest that the Framingham results on the incidence of hypertension [1] can be extrapolated to a Western European population. As in the Framingham study [1], we also

Table 4 Hazard ratios in multiple Cox regression ${ }^{a}$

\begin{tabular}{|c|c|c|c|c|}
\hline \multirow[b]{2}{*}{ Predictor variables } & \multicolumn{2}{|c|}{ Age $<50$ years $(n=1119)$} & \multicolumn{2}{|c|}{ Age $\geq 50$ years $(n=435)$} \\
\hline & Relative hazard ratio & $P$ & Relative hazard ratio & $P$ \\
\hline \multicolumn{5}{|l|}{ Baseline blood pressure category ${ }^{b}$} \\
\hline Optimal & Referent & & Referent & \\
\hline Normal & $2.57(1.90-3.47)$ & $<0.0001$ & $1.71(1.14-2.58)$ & 0.010 \\
\hline High-normal & $3.65(2.60-5.12)$ & $<0.0001$ & $4.34(2.95-6.39)$ & $<0.0001$ \\
\hline \multicolumn{5}{|l|}{ Other baseline characteristics } \\
\hline Female sex (no/yes) & $0.74(0.57-0.95)$ & 0.020 & $1.00(0.74-1.35)$ & $>0.99$ \\
\hline Age $(+10$ years $)$ & $1.36(1.18-1.58)$ & $<0.0001$ & $1.08(0.87-1.34)$ & 0.48 \\
\hline Body mass index $\left(+2 \mathrm{~kg} / \mathrm{m}^{2}\right)$ & $1.10(1.03-1.17)$ & 0.006 & $1.16(1.09-1.24)$ & $<0.0001$ \\
\hline Heart rate $(+10$ beats $/ \mathrm{min})$ & $1.15(1.01-1.31)$ & 0.037 & $1.01(0.86-1.18)$ & 0.93 \\
\hline Smoking (no/yes) & $0.76(0.59-0.99)$ & 0.038 & $1.16(0.83-1.62)$ & 0.38 \\
\hline Change in body mass index $(+5 \%)$ & $1.02(0.95-1.10)$ & 0.53 & $1.04(0.95-1.14)$ & 0.40 \\
\hline
\end{tabular}

Values are hazard ratio (95\% confidence interval). ${ }^{\text {a}}$ Additional adjustment for cohort effects (recruitment before 1996 or later), supplementary baseline characteristics, or both, including alcohol intake, the urinary sodium : potassium ratio, the energy spent in recreational and occupational physical activity, or combinations thereof, did not materially alter the hazard ratios. In individuals younger than 18 years, blood pressure categories were defined according to the thresholds specified by the National High Blood Pressure Education Program Working Group on High Blood Pressure in Children and Adolescents [12]. In participants aged 18 years or older, blood pressure categories relied on the guidelines of the Joint National Committee on the Prevention, Detection, Evaluation and Treatment of High Blood Pressure [2] and the criteria of the World Health Organization and International Society of Hypertension [3].

Table 5 Adjusted ${ }^{a}$ incidence rates of hypertension by baseline blood pressure category ${ }^{b}$

\begin{tabular}{lcc}
\hline Rate per 100 individuals followed up & Age $<50$ years $(n=1119)$ & Age $\geq 50$ years $(n=435)$ \\
\hline 2-year rate & & \\
Optimal & & $8.5(5.8-11.4)$ \\
Normal & $3.8(2.8-4.8)$ & $14.2(10.4-18.1)$ \\
High-normal & $9.4(7.4-11.4)$ & $32.2(26.3-38.6)$ \\
4-year rate & $13.1(9.9-16.5)$ & $16.4(11.2-21.5)$ \\
Optimal & $7.4(5.5-9.3)$ & $26.3(19.8-32.9)$ \\
Normal & $17.9(14.3-21.6)$ & $54.0(45.7-62.3)$ \\
High-normal & $24.5(18.7-30.2)$ & $29.3(21.3-37.4)$ \\
8-year rate & $14.0(10.7-17.2)$ & $44.8(35.8-53.8)$ \\
Optimal & $32.0(26.5-37.6)$ & $77.9(70.1-85.6$ \\
$\quad$ Normal & $42.2(33.9-50.6)$ & \\
High-normal & & \\
\hline
\end{tabular}

${ }^{a}$ Rates were adjusted for sex, age, body mass index, heart rate and smoking at baseline and for the change in body mass index during follow-up. ${ }^{b}$ In individuals younger than 18 years, blood pressure categories were defined according to the thresholds specified by the National High Blood Pressure Education Program Working Group on High Blood Pressure in Children and Adolescents [12]. In participants aged 18 years or older, blood pressure categories relied on the guidelines of the Joint National Committee on the Prevention, Detection, Evaluation and Treatment of High Blood Pressure [2] and the criteria of the World Health Organization and International Society of Hypertension [3]. ${ }^{\circ}$ The 4-year and 8-year incidence rates were calculated by multiple Cox regression. The 2-year rate was extrapolated from the 4-year rate, assuming constant risk. 
noticed a stepwise increase in the incidence of hypertension across the three non-hypertensive blood pressure categories, older individuals being more likely to become hypertensive. Because of the age trends in blood pressure, progression to hypertension was more frequently attributable to DBP as opposed to SBP in younger individuals compared with their older counterparts. Incidence rates of hypertension were similar in older women and men, but in those younger than 50 years were lower in women than in men.

In addition to the Framingham Heart Study [1], to our knowledge, only two other longitudinal surveys $[17,18]$ have assessed progression to hypertension in non-hypertensive individuals randomly recruited from a population, applying JNC VI [2] or WHO-ISH [3] criteria. However, in those two studies $[17,18]$, participants were followed up only once, without information on the interim period. Several prospective studies [19-28] evaluated the longterm incidence of hypertension over intervals ranging from 8 [19] to 26 years [22], or the short-term incidence over 1- to 2-year intervals [27,28]. Direct comparison of these studies with our current observations or with the Framingham findings [1] is problematic. Indeed, some studies considered only DBP [22-24], applied higher blood pressure thresholds [19-21] than the JNG VI [2] or WHO-ISH [3] criteria, determined the incidence of hypertension from a single visit [20,21, 23,24], used an automated oscillometric technique for blood pressure measurements [27,28], included individuals receiving antihypertensive treatment [28], or included only men $[23,26]$.

Despite the great consistency between the Framingham Heart Study [1] and our current observations, it is necessary to account carefully for several design features in comparing the surveys. First, sample size and the number of incident cases of hypertension were substantially larger in the Framingham Heart Study [1]. Secondly, in Framingham, follow-up was organized systemically at 2-year or 4-year intervals, whereas in our study the interval between visits was variable. Thirdly, the age ranges of the younger and older subgroups in the Framingham Heart Study [1] were different than those in our survey: 35-64 years compared with 10-49 years, and 65-94 years compared with 50-77 years, respectively. For children and adolescents, we applied the HBP-CA [12] thresholds instead of the JNC VI [2] or WHO-ISH [3] criteria. Fourthly, at variance with the Framingham Heart Study [1], we used percentage change in BMI rather than in body weight to evaluate the influence of weight gain on the occurrence of hypertension, mainly because, in children and adolescents, increasing body weight also reflects growth. Finally, the Framingham participants were recruited from 1978 to 1994, and our study participants about 10 years later. Several large-scale epidemiological studies [29,30], including Framingham [31], revealed that blood pressure in the population at large shows a trend to decrease over time. Secular trends may therefore be important in the comparison of longitudinal studies. Compared with those enrolled later, our untreated individuals recruited before 1996 had slightly higher SBP, but similar DBP and incidence of hypertension.

Hypertension is a dichotomous trait. Changes in blood pressure were therefore highly dependent on the baseline value [32]. At enrollment, we also found significant gradients in known risk factors for hypertension across the three non-hypertensive blood pressure categories, in particular BMI and heart rate. In our study, at variance with findings of the Framingham Heart Study [1], the percentage change in BMI (or body weight; data not shown) did not significantly predict the progression to hypertension as a dichotomous outcome, possibly because our participants included 593 individuals $(40.7 \%)$ younger than 35 years, or because in our younger subgroup, BMI was approximately $1-2 \mathrm{~kg} / \mathrm{m}^{2}$ less than that reported in the Framingham study [1]. However, in continuous analyses, especially in the younger subgroup, we found, in line with the Framingham results [1] and those of a recently reported Norwegian study [33], a positive and independent association between the increase in blood pressure and BMI at baseline.

The Framingham investigators adjusted their analyses for baseline characteristics, but they did not report the relative risks for smoking coded as yes/no. Smoking acutely increases blood pressure and heart rate through sympathetic stimulation [34]. In contrast, in our Flemish population [35] and in other epidemiological surveys [35], in which blood pressure was measured after a tobaccofree interval, smokers on average had a $2-3 \mathrm{mmHg}$ lower SBP than non-smokers. This may result from the reduction in sympathetic activity in the intervals between smoking or from the development of tolerance [36]. In the British Health and Lifestyle Survey [18], the occurrence of hypertension was also not significantly related to the use of tobacco. However, in our younger subgroup, heart rate was a strong predictor of hypertension. Findings of the Tecumseh study [37] and other surveys [38] suggested that a faster heart rate in young individuals is a risk factor for hypertension, and that it coincides with obesity, dyslipidemia, insulin resistance and a parental history of a hyperdynamic circulation [39]. Sympathetic overactivity is likely to explain these associations [37-39]. In line with the findings of other withinpopulation studies [40], we could not demonstrate a significant association between the risk of hypertension and the urinary sodium : potassium ratio, probably because of the high variability in the urinary measurements. The most convincing evidence for a role of salt in the pathophysiology of hypertension comes from experimental studies [41] and interventional trials $[42,43]$. 
Cross-sectional and longitudinal studies of populations of developed countries demonstrated that SBP increases with age at least until the eighth decade of life, whereas DBP increases only until middle age, and thereafter levels off, or even decreases [44]. In comparison with the Framingham results [14], reported almost 30 years ago, we observed great similarity in the age-related trends in SBP and DBP, if the analyses were based on longitudinal data. However, in the cross-sectional analysis of Framingham men, SBP continued to increase only until the seventh decade of life, and DBP declined only after age 56 years. Selective survival of participants with lower SBP might have contributed differentially to the crosssectional observations in Framingham [14] and our current study.

The confirmation of the Framingham findings in a Western European population has clinically important implications. The most recent guidelines of the Joint National Committee on the Prevention, Detection, Evaluation and Treatment of High Blood Pressure recognize that prehypertension, the combination of normal and high-normal blood pressure as defined in the current study, represents a major public health problem [4]. The Trial of Preventing Hypertension [28] recently showed that the early treatment of prehypertension might ameliorate the natural history of subsequent hypertension. In addition, further research according to the Framingham design [1] should document the rates of progression to hypertension in non-hypertensive individuals of Asian and Black ancestry. Previous studies [20,25] demonstrated that the incidence of hypertension is twice as high in Black as in White Americans. On the basis of the Framingham findings [1,45], yearly screening might be appropriate for individuals with high-normal blood pressure, whereas for those with normal blood pressure, follow-up visits might be scheduled at intervals of 23 years in older and younger individuals, respectively.

In conclusion, the stepwise increase in the incidence of hypertension across the three non-hypertensive blood pressure categories in our cohort was similar to that observed in the Framingham Heart Study [1]. Despite differences in the prevalence of hypertension between continents and countries [6], the Framingham findings on the progression to hypertension, which informed several guidelines for the diagnosis and management of hypertension [4,5], can be extrapolated to a Western European population.

\section{Acknowledgement}

The Flemish Study on Environment, Genes and Health Outcomes (FLEMENGHO) is part of the European Project on Genes in Hypertension (EPOGH), which is endorsed by the European Council for Cardiovascular Research and the European Society of Hypertension. FLEMENGHO would not have been possible without the voluntary collaboration of the participants and their general practitioners. The municipality of Hechtel-Eksel (Belgium) gave logistic support. The investigators contributing to FLEMENGHO and EPOGH are listed in reference [35]. The authors gratefully acknowledge the technical assistance of Sandra Covens, Lieve Gijsbers, Marie-Jeanne Jehoul, Hanne Truyens, Sylvia Van Hulle and Renilde Wolfs (Studies Coordinating Centre, University of Leuven, Belgium).

\section{References}

1 Vasan RS, Larson MG, Leip EP, Kannel WB, Levy WD. Assessment of frequency to progression to hypertension in non-hypertensive participants in the Framingham Heart Study: a cohort study. Lancet 2001; 358:16821686.

2 The Joint National Committee on Prevention Detection Evaluation and Treatment of High Blood Pressure. The sixth report of the Joint National Committee on Prevention, Detection, Evaluation, and Treatment of High Blood Pressure (JNC VI). Arch Intern Med 1997; 157:24132446.

3 Guidelines Subcommittee. 1999 World Health Organization-International Society of Hypertension guidelines for the management of hypertension. J Hypertens 1999; 17:151-183.

4 Chobanian AV, Bakris GL, Black BK, Cushman WC, Green LA, Izzo JL Jr, et al. Seventh report of the Joint National Committee on Prevention, Detection, Evaluation, and Treatment of High Blood Pressure. Hypertension 2003; 42:1206-1252.

5 Hemmelgarn BR, Zarnke KB, Campbell NR, Feldman RD, McKay DW, McAlister FA, et al. The 2004 Canadian Hypertension Education Program recommendations for the management of hypertension: Part I - Blood pressure management, diagnosis and assessment of risk. Can J Cardiol 2004; 20:31-40.

6 Wolf-Maier K, Cooper RS, Banegas JR, Giampaoli S, Hense HW, Joffres $\mathrm{MR}$, et al. Hypertension prevalence and blood pressure levels in 6 European countries, Canada, and the United States. JAMA 2003; 289:2363-2369.

7 Staessen JA, Roels HA, Emelianov D, Kuznetsova T, Thijs L, Vangronsveld $\mathrm{J}$, et al. Environmental exposure to cadmium, forearm bone-density, and risk of fractures: prospective population study. Lancet 1999; 353:1140-1144.

8 Li Y, Thijs L, Kuznetsova T, Zagato L, Struijker-Boudier H, Bianchi G, et al. Cardiovascular risk in relation to $\alpha$-adducin Gly460Trp polymorphism and systolic pressure. A prospective population study. Hypertension 2005; 46:527-532.

9 Staessen JA, Bieniaszewski L, Pardaens K, Petrov V, Thijs L, Fagard R. Life style as a blood pressure determinant. J Royal Soc Med 1996; 89:484489.

10 Astrand PO, Rodahl K. Textbook of work physiology. Physiological bases of exercise. New York, NY, USA: McGraw-Hill Book Company; 1986.

11 American Diabetes Association. Screening for type 2 diabetes. Diabet Care 1999; 22 (suppl 1):S20-S23.

12 National High Blood Pressure Education Program Working Group on Hypertension Control in Children and Adolescents. The Fourth Report on the Diagnosis, Evaluation, and Treatment of High Blood Pressure in Children and Adolescents. Pediatrics 2004; 114:555-576.

13 Laboratorium voor Antropogenetica, Vrije Universiteit Brussel, Brussels, Belgium. Growth Charts Flanders 2004 (Accessed 6 November 2005. at http://www.vub.ac.be/groeicurven/english.html.).

14 Kannel WB, Gordon T. Evaluation of cardiovascular risk in the elderly: the Framingham study. Bull N Y Acad Med 1978; 54:573-591.

15 MacMahon S, Peto R, Cutler J, Collins R, Sorlie P, Neaton J, et al. Blood pressure, stroke, and coronary heart disease. Part 1, Prolonged differences in blood pressure: prospective observational studies corrected for the regression dilution bias. Lancet 1990; 335:765-774.

16 Staessen JA, Gasowski J, Wang JG, Thijs L, Den HE, Boissel JP, et al. Risks of untreated and treated isolated systolic hypertension in the elderly: metaanalysis of outcome trials. Lancet $2000 ; 355: 865-872$.

17 Carbajal HA, Salazar MR, Rionder B, Quaini SM, Rechifort VE, Rodrigo HF, et al. Ten-year blood pressure trends in nonhypertensive inhabitants of $\mathrm{La}$ Plata, Argentina. Can J Cardiol 1998; 14:917-922.

18 Winegarden CR. From 'prehypertension' to hypertension? Additional evidence. Ann Epidemiol 2005; 15:720-725.

19 Garrison RJ, Kannel WB, Stokes J III, Castelli WP. Incidence and precursors of hypertension in young adults: the Framingham Offspring Study. Prev Med 1987; 16:235-251. 

impact of hypertension in the United States. The National Health and Nutrition Examination Survey I Epidemiologic Follow-up Study. Arch Intern Med 1989; 149:780-788.

21 Ford ES, Cooper RS. Risk factors for hypertension in a national cohort study. Hypertension 1991; 18:598-606.

22 Leitschuh M, Cupples LA, Kannel W, Gagnon D, Chobanian A. Highnormal blood pressure progression to hypertension in the Framingham Heart Study. Hypertension 1991; 17:22-27.

23 Skarfors ET, Lithell HO, Selinus I. Risk factors for the development of hypertension: a 10-year longitudinal study in middle-aged men. $J$ Hypertens $1991 ; 9: 217-223$.

24 Bakx JC, van den Hoogen $\mathrm{HJ}$, van den Bosch WJ, van Scayck CP, van Ree JW, Thien T, et al. Development of blood pressure and the incidence of hypertension in men and women over an 18-year period: results from the Nijmegen cohort study. J Clin Epidemiol 1999; 52:531-538.

25 Dyer AR, Liu K, Walsh M, Kiefe C, Jacobs DR Jr, Bild DE. Ten-year incidence of elevated blood pressure and its predictors: The CARDIA Study. J Hum Hypertens 1999; 13:13-21.

26 Kawasaki T, Uezono K, Sanefuji M, Utsunomiya H, Fujino T, Kanaya S, et al. A 17-year follow-up study of hypertensive and normotensive male university students in Japan. Hypertens Res 2003; 26:445-452.

27 Radi S, Lang T, Lauwers-Cances V, Chatellier G, Fauvel JP, Larabi L, et al. One-year hypertension incidence and its predictors in a working population: the IHPAF study. J Hum Hypertens 2004; 18:487-494.

28 Julius S, Nesbitt SD, Egan BM, Weber MA, Michelson EL, Kaciroti N, et al. Feasibility of treating prehypertension with an angiotensin-receptor blocker. N Engl J Med 2006; 354:1685-1697.

29 Burt VL, Cutler JA, Higgins M, Horan MJ, Labarthe D, Whelton P, et al. Trends in the prevalence, awareness, treatment, and control of hypertension in the adult US population. Data from the Health Examination Surveys, 1960 to 1991. Hypertension 1995; 26:60-69.

30 Rosengren A, Eriksson H, Larsson B, Svardsudd K, Tibblin G, Welin L, et al. Secular changes in cardiovascular risk factors over 30 years in Swedish men aged 50: the study of men born in 1913, 1923, 1933 and 1943. J Intern Med 2000; 247:111-118.

31 Kannel WB, Garrison RJ, Dannenberg AL. Secular blood pressure trends in normotensive persons: the Framingham Study. Am Heart J 1993; 125:1154-1158.

$32 \mathrm{Wu} \mathrm{M}$, Ware JH, Feinleib M. On the relation between blood pressure change and initial value. J Chron Dis 1980; 33:637-644.

33 Droyvold WB, Midthjell K, Nilsen TI, Holmen J. Change in body mass index and its impact on blood pressure: a prospective population study. Int $J$ Obes (Lond) 2005; 29:650-655.

34 Zhang J, Kesteloot $\mathrm{H}$. Anthropometric, lifestyle and metabolic determinants of resting heart rate. A population study. Eur Heart J 1999; 20:103-110.

35 Stolarz K, Staessen JA, Kuznetsova T, Tikhonoff V, State D, Babeanu S, et al. Host and environmental determinants of heart rate and heart rate variability in four European populations. J Hypertens 2003; 21:525-535.

36 Benowitz NL, Sharp DS. Inverse association between serum cotinine and blood pressure. Circulation 1989; 80:1309-1312.

37 Julius S, Valentini M, Palatini P. Overweight and hypertension. A 2-way street? Hypertension 2000; 35:807-813.

38 Palatini P, Casiglia E, Pauletto P, Staessen J, Kaciroti N, Julius S. Relationship of tachycardia with high blood pressure and metabolic abnormalities. A study with mixture analysis in three populations. Hypertension 1997; 30:1267-1273.

39 Palatini P, Vriz O, Nesbitt S, Amerena J, Majahalme S, Valentini M, et al. Parenteral hyperdynamic circulation predicts insulin resistance in offspring. Hypertension 1999; 33:769-774.

40 Staessen JA, Lijnen P, Thijs L, Fagard R. Salt and blood pressure in community-based intervention trials. Am J Clin Nutr 1997; 65 (2 suppl): 661S-670S.

41 Denton D, Weisinger R, Mundy NI, Wickings EJ, Dixson A, Moisson P, et al. The effect of increased salt intake on blood pressure of chimpanzees. Nat Med 1995; 1:1009-1016.

42 Graudal NA, Galloe AM, Garred P. Effects of sodium restriction on blood pressure, renin, aldosterone, catecholamines, cholesterols, and triglyceride: a meta-analysis. JAMA 1998; 279:1383-1391.

43 Sacks FM, Svetkey LP, Vollmer WM, Appel LJ, Bray GA, Harsha D, et al. Effects on blood pressure of reduced dietary sodium and the Dietary Approaches to Stop Hypertension (DASH) diet. DASH-Sodium Collaborative Research Group. N Engl J Med 2001; 344:3-10.

44 Staessen J, Amery A, Fagard R. Isolated systolic hypertension in the elderly. J Hypertens 1990; 8:393-405. (Editorial review.)

45 Vasan RS, Levy D. Rates of progression to hypertension among non-hypertensive subjects: implications for blood pressure screening. Eur Heart J 2002; 23:1067-1070. 